\title{
A Survey of Economic Modelling of Sustainable Development ${ }^{1}$
}

\author{
Jeroen C.J.M. van den Bergh \\ Department of Spatial Economics \\ Faculty of Economics and Econometrics \\ Vrije Universiteit \\ De Boelelaan 1105 \\ 1081 HV Amsterdam \\ e-mail:jbergh@econ.vu.nl \\ Marjan W. Hofkes \\ Institute for Environmental Studies \\ Vrije Universiteit \\ De Boelelaan 1115 \\ 1081 HV Amsterdam \\ e-mail: marjan.hofkes@ivm.vu.nl
}

1 Comments by Frank den Butter, Klaus Conrad, Peter Nijkamp, David Pearce and Richard Tol are gratefully acknowledged. Evidently, we are responsible for all views expressed as well as for all remaining errors. 


\begin{abstract}
An overview is offered of different approaches to economic modelling of sustainable development. First, conceptual-theoretical perspectives on sustainable development are shortly reviewed from the angle of model implications. Next, different model types are discussed. These include neoclassical growth models, sectorally disaggregated models, and integrated and co-evolutionary models. Special attention is also devoted to discounting in the context of concern for future generations, and to empirical issues involved in modelling for sustainable development.
\end{abstract}




\section{Introduction}

This chapter presents a broad overview of types of formal models of sustainable development. Sustainable development has become a common term in environmental economics. Without immediately offering a rigorous definition, one can safely state that it is generally agreed upon that sustainable development refers to the long-run mutual dependence of environmental quality and resource availability on the one hand, and economic development on the other hand. More specifically, it is related to casting the environment explicitly in the context of economic growth and development. This is about as far as the consensus goes, since the specific goals adhered to diverge between supporters of the (anthropocentric) criterion of intergenerational justice (or more narrowly intergenerational equity), and the (non- or less anthropocentric) environmental rights criterion. ${ }^{2}$

Why present an overview of models of sustainable development? Any analysis of sustainable development, on a general theoretical level, but also in particular applications, means that one has to solve complicated analytical problems, due to the focus on long-run processes, and, associated with this, due to the complete or system-wide perspective. This implies that one has to address the complexity of relationships between actors and components of the economy-environment system over time. Models can help us, to some extent, in dealing with such complexity, also since there is much support nowadays from numerical and computer-based methods in dealing with increased model complexity. Therefore, the use of traditional, externality-based models can be complemented by a mix of sustainable development models. ${ }^{3}$ This mix could comprise a wide variety of model types and theories, as indicated hereafter. Both theoretical and empirical models can be used to deal with aspects of structure, dynamics and management of economies. Such models can address questions like: is maintenance or (re)production of the necessary environmental conditions for the continued operation of economies possible; what net or synergetic effect on economic development results from diminishing returns of resources in production, new resource discoveries, technical progress and substitution processes on the level of production and consumption; and, is a stationary state a necessary and possible end phase, or will economies inevitably continue to expand. Such questions may be dealt with by modelling physical and

\footnotetext{
2 These rather extreme positions can be related to ethical positions such as expressed by Rawls' theory of justice (Rawls, 1972) and the Deep Ecology movement (e.g., D evall and Sessions, 1984). This does not necessarily imply that the goals lead to different conclusions in all respects, as, for instance, species preservation may certainly be consistent with intergenerational justice.

${ }^{3}$ Some of the models can be regarded as making the externality explicit in space or time by adding ecosystem process descriptions and linking these to economic activities (Crocker and T schirhart, 1992).
} 
resource limits, or biological limits, or even both. The main problem seems to be the linkage between growth in value and long run impacts in biological and physical terms. Of course, there is no doubt that many important issues remain unresolved by model exercises of this kind, and we certainly do not make a plea to restrict the attention to formal modelling in the search for insights about sustainable development.

When examining suitable models for sustainable development analysis, one can find large differences, due to distinct theoretical starting points and, linked to these, alternative demarcations of the complex problem associated with the overall objective of sustainable development. Some models focus on technology, while others extend upon natural process description, and again others address social or evolutionary processes. We do not argue that there is one best modelling approach, but rather that an array of models is available that provides different, and largely complementary insights.

As the literature on sustainable development and related theoretical and empirical studies is diverse, a single comprehensive overview is lacking. An overview of neoclassical models of sustainable development is given by Toman, Pezzey and Krautkraemer (1995) and Heal (1996). A broader perspective on models for sustainable development, with special attention for integrated models, can be found in Van den Bergh (1996). Evolutionary models addressing sustainable development issues are discussed in Clark, Perez-Trejo and Allen (1995). A recent book by Faucheux, Pearce and Proops (1996) offers a variety of formal modelling studies in the context of sustainable development.

In the next section different conceptual-theoretical perspectives on sustainable development are shortly reviewed from the angle of model implications. In subsequent sections, attention will be paid to neoclassical models, discounting, sectorally disaggregated models, integrated and (co)evolutionary models, and other empirical model-based studies. Some suggestions for further research are presented in a final section.

\section{Defining and interpreting sustainable development}

The concept of sustainable development has over a rather short period of time become commonplace in environmental economics. There is, however, some confusion about the use of the terms sustainability and sustainable development. Goodland (1995) distinguishes environmental sustainability, economic sustainability, social sustainability and sustainable development. Environmental sustainability is defined as maintenance of life-support systems (both sinks and sources). Economic sustainability is the economic tantamount of 
environmental sustainability, being defined as maintenance of economic capital. This definition of economic sustainability falls back on the Hicksian definition of income (Hicks, 1939): the maximum amount of income that can be spent without reducing real consumption in the future. Social sustainability is defined as maintenance of social capital. Sustainable development should integrate the three types of sustainability and use them to start to make development sustainable. While it is difficult to find agreement on definitions of environmental and economic sustainability (let alone social sustainability), sustainable development is an even more ambiguous concept. The Brundtland definition (WCED, 1987) of sustainable development being "development that meets the needs of the present without compromising the ability of future generations to meet their own needs", which is based on intergenerational equity, is used in a large part of the mainstream economic literature. However, there are also other perspectives possible. Each perspective uses, directly or indirectly, its own (subjective) choice for a certain welfare concept (maximin, (discounted) utilitarian, Chichilnisky criterion) and its own trade-off between present and future generations (i.e. choice of discount rate). So, sustainable development in fact is a normative concept. This will be discussed further below.

Initially, economists have been rather sceptical about the use of the concept sustainable development in economics - and indeed many still are - but more and more economists accept its relevance and recognize its value added. For many economists sustainable development comes down to issues of equity between generations and as such adds to the notion of efficiency in terms of optimal allocation. The concept of optimal allocation occupies a central position in externality (welfare) theory, both in static and - in the present context more relevant - intertemporal settings. To other economists the goal of sustainable development is essentially putting a restriction on the physical scale of an economy.

From a modelling perspective the following distinction of interpretations of sustainable development is useful:

1. Discounted utilitarianism. The present discounted value of utility is the commonly used criterion in models of optimal economic development. Sustainable development can be integrated naturally in this framework by fully specifying economy-ecology interactions with respect to both production processes and welfare. In this approach a broadly defined welfare-function should be used, which also includes environmental quality (see Hofkes, 1996). Under a positive discount rate, however, the (very) long run does not get 
much weight. Some argue that, since the utililitarian approach does not capture the far future, this approach is less apt for the valuation of environmental issues, like climate change, of which the consequences become apparent only in the very long run. If society wants to give more weight to the very long run another welfare criterion might be needed. Chichilnisky (1993) develops a criterion which boils down to adding a term which values the very long run (or limiting) behaviour of the economy. Alternatively, (normative) restrictions concerning equity between generations and/or (absolute) levels of environmental quality can be added.

2. Intergenerational equity. In economic growth theory sustainable development is often translated into intergenerational equity. This is operationalized with the restriction of non-decreasing welfare, which comes down to non-decreasing welfare over time in single-generation models, or non-decreasing welfare over generations in discretegenerations models. Pezzey (1989/1992) has referred to "sustainedness" in this respect since such a pattern can be assessed only after the fact. Intergenerational equity represents a strict criterion, as it regards any temporary decrease as a sign of unsustainable development. As an alternative objective Pezzey refers to "survivability", under which it is allowed to undergo a reduction of welfare as long as the level of consumption exceeds some subsistence level. A special case is where consumption rather than utility is required to be constant or increasing over time (the "Hicksian sustainability" discussed above).

3. Weak sustainability. A different starting point is that of maintaining total capital. This is also referred to as weak sustainability. It typically allows for substitution between manmade and natural capital (see Pearce et al., 1990). The practical expression of this has been to focus attention on equal opportunities for present and future generations. Neoclassical models fit this type of perspective ideally and the standard methodology applied by economists to investigate such equal opportunities has been once again in terms of implied utility patterns over time. Although having different starting points, intergenerational equity and weak sustainability can lead to similar conclusions. Common and Perrings (1992) define this as Solow/Hartwick-sustainability (see Hartwick, 1977; and Solow, 1986). For more discussion of weak sustainability see Gutés (1996). 
4. Strong sustainability. Under strong sustainability different types of capital (economic, ecological, social) should be independently maintained in physical/biological terms. The motivation for this standpoint is either the recognition that natural resources are essential inputs in economic production, consumption or welfare that cannot be substituted for by physical or human capital, or the acknowledgement of environmental integrity and rights in nature. In either case it is understood that environmental components are unique and that environmental processes may be irreversible (over relevant time horizons). Very strong sustainability (like supported by the Deep Ecology movement) would then imply that every component or subsystem of the natural environment and every physical stock is to be preserved (see Pearce and Atkinson, 1995). This seems almost impossible, also in view of continuous processes of natural change. A somewhat weaker version would focus on ecosystems and environmental assets that are critical in the sense of providing unique services (such as life-support) or non-use values. Another weaker version is that a minimum amount of certain environmental assets should be maintained, such that these assets are partly complementary to economic assets and partly substitutable by the latter. The practical expression of the strong sustainability concept is in terms of preservation of species, safe minimum standards for impacts on environmental quality and sustainable use of renewable natural resources. Preservation of the physical size of non-renewable resources would mean leaving them unused. One can interpret this criterion as derived from physical and ecological constraints (carrying capacity) receiving priority over everything else. Clearly, although weak and strong sustainability are usually mentioned in one and the same breath, their formalization differs completely, since strong sustainability as opposed to weak sustainability does not allow for any substitution between the different kinds of capital.

5. Stationary state. Daly has since long forcefully argued in favour of the idea of a stationary state, where population and economic stocks are maintained (Daly, 1977/1991). With regard to man-made economic stocks of capital, "constancy" is perhaps not an entirely suitable qualification, as the physical size of these stocks should remain constant but the quality (value) could well be improved. In this perspective, the main social aim of development should be to minimize human impacts on the natural environment, by minimizing the material and energetic throughput of human production 
and consumption, subject to a constant level of consumption or per capita income. It is not entirely clear though whether the latter should relate to the initial (accidental) level of welfare, or be equal to some subsistence level of consumption. A stationary state means an entirely different development-objective than that posed by standard economics, though it still leaves open opportunities for improvement in living conditions and welfare. An alternative viewpoint on this objective is in terms of optimal scale of the economy, which Daly points out should complement the standard economic concept of optimal allocation (e.g., Daly, 1987 and 1992). Although its starting point and emphasis is different, the strong sustainability perspective is likely to lead to similar conclusions as Daly's perspective.

6. Ecological stability and resilience. Many ecologists would allegedly support the idea that environmental sustainability is mainly a matter of stability, resilience and biotic diversity. ${ }^{4}$ Common and Perrings (1992) refer to this as ecological Hollingsustainability (Holling, 1973). The standard neoclassical oriented models do not address fluctuations and $\mathrm{cycles}^{5}$, nor do they incorporate any real ecosystem structure. In order to be able to deal with stability and uncertainty in a way consistent with ecological theory, integration of economic and ecological models is necessary. Integrated models, and especially (co)evolutionary models, seem the obvious tools for dealing with this linkage problem (see Section 6). This perspective can be linked to the one of strong sustainability, by recognizing that maintenance of natural capital does require a precautionary approach which takes safety margins into account, as stability is not guaranteed by operating at the margin of optimal levels of capital.

It should be noted that the above mentioned perspectives or starting points are not necessarily in disagreement with each other. It is possible that they give rise to similar or identical conclusions on a general level or in specific cases. Important is, however, that they may also

\footnotetext{
${ }^{4}$ A ccording to Common and Perrings (1992) stability means that variables return to equilibrium values after perturbation. Resilience

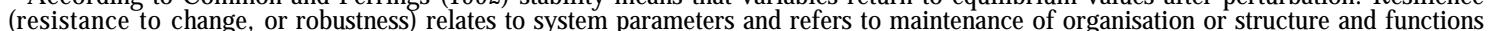
of a system. Resilience can be considered as a global, structural stability concept, and may cover multiple locally stable equilbria. In other words, stability of a local equilibrium of a system implies resilience of the respective system, but resilience does not necessarily other words, stability of a local equilibrium of a system implies resilience of the respective system, but resilience does not necessarily
go along with stability of a (each) local equilibrium. These concepts are usually considered in the context of ecosystem structure and processes. Sustainability can then be interpreted as resilience to external influences such as climate or human influences.

${ }^{5}$ Business cycle theories would seem adequate in this respect, e.g., using $\mathrm{H}$ arrod-D omar and multiplier-accelerator models (see $\mathrm{Y}$ oung, 1996). Indeed, a main unanswered question is why other types of dynamic macro-economics than growth theory have seen so little application in environmental economics, for instance, to address questions related to the interaction between sustainability and unemployment.
} 
lead to different and possibly conflicting conclusions, in which case one has to make a choice. In view of the present literature, and the fundamental differences of perspectives/starting points this seems largely a subjective issue from which we will sidestep here. This may be casted in a more fundamental setting of ethics and epistemology.

\section{Economic growth theory}

Economists have devoted much effort to formal analysis of the conditions under which economic growth is sustainable. The main focus of these analyses is whether optimality (efficiency) can be harmonized with sustainability. For this purpose alternative social objectives and alternative production relationships have been examined.

The neoclassical Solow type of growth model has long served as the benchmark in dealing with the question of limits to growth, either on the basis of resource scarcity or environmental pollution, or both. Over the last decade attention has shifted to modern growth theory (see e.g. Beltratti, 1996; Bovenberg and Smulders, 1995; Hofkes, 1996; and Smulders in this book). The various assumptions and their implications can best be illustrated by considering a general growth-with-environment model as shown in appendix 1. This model includes the following main elements (numbers refer to model equations):

(1) A social objective, possibly reflecting welfare of multiple generations over time; the standard neoclassical assumption is that of a net present value function, based on applying a given discount rate to future net benefits (utility); welfare may involve environmental stocks (preservation goal) and bequest values (intergenerational equity goal).

(2) A production function, combining man-made and environmental stocks and flows as primary inputs to produce final goods and services.

(3) A dynamic description of the economy, resulting from investment in, and depreciation of man-made capital.

(4)-(6) A dynamic description of the environment, resulting from resource exhaustion (4), natural regeneration (5) and pollution assimilation (6).

(7) The distribution of output, usually restricted to consumption (C) and investment (I); when more activities and capital stocks are distinguished between, this will be reflected by more categories of outlays in this balance equation.

(8) Initial conditions on all cumulative (state) variables. 
Of course, even this model is not general enough to incorporate the many types of specifications that have been published (see for a good entrance to the literature Kamien and Schwarz, 1982; and Toman et al., 1995). The global model structure may change when additional activities and economic capital are defined, such as related to recycling, abatement and innovation (the latter leading to the new growth theory).

There are several options to incorporate sustainability in the above general class of models or in the related model analyses:

(i) Finding the optimal (efficient) dynamic solution and testing whether it satisfies the chosen definition or interpretation of sustainable development. The disadvantage is that this is likely to render a negative outcome. In that case one should solve one of the problems mentioned under (ii) and (iii).

(ii) Explicitly incorporating sustainability as a condition, on the stock of environmental resources or assimilative capacity, on consumption patterns or more generally on welfare changes. Then a (complicated) dynamic optimization problem with inequality constraints has to be solved. The outcome of this will be a sustainable development path. This approach thus retains the standard social objective function while adding constraints.

(iii) Another option is to change the social objective function, for example by explicitly giving a larger weight to the welfare of generations in the distant future. Heal (1996) refers to the Chichilnisky criterion as a way to incorporate intergenerational equity in the optimality criterion in this manner, i.e. without adding any separate condition. This criterion is a weighted average of a discounted integral of utilities (i.e. the standard neoclassical criterion) and a term that depends on the long-run properties of the stream of utility. The latter term would reflect concern for the long-run future, while the weighted average would assure that neither the present nor the future are dictatorial. 
Each of the above options can be considered in combination with a non-renewable resource, a renewable resource or a combination of these. ${ }^{6}$ The case of non-renewable resources has attained most attention, as it is the most simple representation of the essential features of the growth-environment conflict, as fossil fuels are dominating resource and energy analysis, and as all other models are analytically more complex. With regard to sustainability and nonrenewable resources there are two positions possible. First, one can argue that strong sustainability implies that these resources are not exploited at all. An alternative position would be to strive for weak sustainability, i.e. keeping total capital intact. The most important result for this case is the Hartwick rule, which can be stated as follows: investment of the Hotelling scarcity rents from exploitation of the non-renewable resource in man-made capital results in maximum constant consumption over time, given the initial conditions (Hartwick, 1977, 1978a,b; Solow, 1986; Hamilton, 1995; Gutés, 1996). This result depends critically on assumptions about the production function. The approach is regarded as weak sustainability, as complete substitution between natural and man-made capital is allowed for. ${ }^{7}$ A related concept is the "Green Golden Rule of Economic Growth" defined as the highest level of consumption that can be indefinitely maintained (independent of initial conditions), given environmental and resource constraints (see Heal, 1996).

In case the resource is not essential, one may decide to aim for intergenerational equity through a "fair and sensible way to use up these [...] resources" (Pezzey, 1995, p.1). Pezzey (ibid.) establishes that maximizing the present discounted value of utility (PV) can be unfair, as it may lead to misery for distant generations. He examines "Opsustimality" in the case of production with inputs from man-made capital and a non-renewable resource. Maximizing $\mathrm{PV}$, provided that utility is non-declining, leads then to a path on which utility is constant and possibly increasing over a finite period.

Neoclassical growth theory with resources and environment has received much attention in the 1970s and 1980s. Although most economists would agree that one of the main factors of economic development is technological progress, only since the end of the 1980's new growth theories have been developed that regard technology as endogenous to the economy. The case

\footnotetext{
${ }^{6} \mathrm{~N}$ ext, assuming that only pollution stress is significant in the long run implies a model which focuses entirely on the long-run impact of emission and dumping of waste. It should be noted here that on a general abstract level of analysis the distinction between assimilation and regeneration is not essential, as inclusion of either proces generates similar insights. The reason for this is that the assimilation and regeneration is not essential, as inclusion of either proces generates similar insights. The reason for this is that the
general characteristics of the two processes as reflected in the abstract growth model formulations are very similar. Finally, a
combination of growth in a closed system with non-renewable resources and pollution (or renewable resources) is very rare, since the resulting analysis is clearly very complicated (see Tahvonen and Kuuluvainen, 1991 and 1993).

7 The need for resource materials in production is included in the weakest sense possible, namely via the "essentiality" assumption, meaning that production is only zero if resource inputs are zero. If resource materials are not essential in this sense, then it it will be optimal to exhaust the resource under weaker conditions than when they are essential.
} 
of renewable resources is mainly analyzed within the context of such endogenous (or modern) growth models (see e.g. Gradus and Smulders, 1993). These models are solved by looking at (optimal) balanced growth solutions, i.e. growth paths on which all variables grow with a constant (possibly zero) growth rate. It is shown that under certain conditions with respect to production and substitution elasticities there is an optimal growth path on which the economy grows at a constant positive growth rate, keeping environmental quality (or stock of renewable resources) at a constant level. In such models growth in technology and abatement together with self-regenerating capacities of the natural environment compensate for growth in use of natural resources (see Hofkes, 1996).

The above mentioned growth models deal with continuous time (optimal control) problems, which means that no clear distinction can be made between generations. Consequently, it is not possible to distinguish between generation-specific social welfare terms. A discrete (dynamic programming) approach, in which each generation is supposed to exist during a certain period, allows one to deal with a number of issues, notably, alternative intergenerational welfare functions (maximin), overlap between generations, and altruism. The continuous-time neoclassical models and the discrete generations models focusing on a present value type of social welfare function can be criticized as putting too much weight on the welfare of the present or nearby generations. Starting from a discrete multi-generational perspective also allows one to study other types of social welfare functions. The neoclassical net present value approach can be replaced by a maximin function, based on an egalitarian principle, where the objective is to maximize the outcome of the worst-off generation (see, e.g., Arrow, 1973; Solow, 1974; Asako, 1980; John et al., 1995). ${ }^{8}$ The main lesson from these various contributions is that based on the maximin criterion initial conditions may completely dominate the long run potential development. More specifically, under this criterion, if the initial generation is also the poorest, i.e. has little man-made, productive capital, it will not be allowed to save and invest in productive capital to increase the wealth of future generations. In other words, when the initial generation is poor, all future generations will be poor as well.

In addition to considering alternative social objectives, a fundamental issue is how to

\footnotetext{
${ }^{8}$ This intergenerational maximin criterion is often referred to as an intertemporal extension of Rawls' indifference notion, developed as part of a contractual theory ("theory of justice"), where a hypothetical situation is created in which individuals of a society have to come to an agreement about principles of justice. One such principle is the difference principle, translated to a maximin criterion (Rawls, 1972). The choice is made under a "fair situation", namely "behind a veil of ignorance", where individuals have no knowledge about their effective place in society, and neither of their possession of abilities and assets. Some problems have been indicated with regard to this approach: that Rawls' approach cannot be extended to intertemporal problems; and that the maximin criterion is not consistent with Pareto efficiency. To solve the first critique. Harsanyi's maximin approach to decision-making under uncertainty is sometimes mentioned as a starting point (Harsanyi, 1955). Finally, the maximin criterion can be regarded as a limiting special case of utilitarianism, also referred to as egalitarianism (see K neese and Schulze, 1985).
} 
incorporate materials balance conditions. It is easily shown that growth will be finite when consumption and other economic variables are interpreted in terms of material units, and checked via materials balance, which effectively means that complementarity of inputs is emphasized (see Gross and Veendorp, 1990). This brings us, however, to a fundamental issue, namely to what extent resource scarcity and pollution can be circumvented by producing more value from less materials. Two mechanisms support such trends, namely substitution from material (and energy) inputs to non-material inputs (services obtained from capital and labour) and resource saving technological progress (whether process-integrated or end-ofpipe/recycling). Georgescu-Roegen (1971) has forcefully argued that capital and labour cannot be set on an equal level with materials as inputs to production functions. The reason is that the services and not the "cumulative stocks" of capital and labour are the real inputs. Furthermore, capital and labour are no stocks in the precise meaning of the word. The latter namely indicates entities that can be emptied or filled at any speed, while capital and labour can only generate a limited number of services over a given finite period. Georgescu-Roegen uses the term "fund" for this. Although substitution among funds or among materials is quite straightforward, substitution between these two categories is less evident, given these peculiar features of capital and labour. Instead one should focus on complementarity of funds and materials. The conclusion that even without technological progress substitution can sustain infinite growth on a finite non-renewable resource base is established on assumptions which conflict with the complementary role of material inputs and service inputs supplied by the "funds". Even if there is great potential of creating (finite) value added, it should be realized that services require still a positive level of material and energy support, certainly when including total, indirect effects, such as implicit in the models discussed here. Unlimited materials-saving technological progress seems thus unrealistic.

Finally, it must be noted that the overview here is necessarily incomplete, and does not deal with issues like, for instance, uncertainty (see, e.g., Baranzini and Bourguignon, 1995; and Perrings, 1991). Generally, uncertainty with regard to non-use values, option and quasi-option values, future population size, preferences, technological progress and natural phenomena would lead to more conservative use of both non-renewable and renewable resources. Multicountry analyses dealing with a combination of trade and resource use over time are rare as well. 


\section{Discounting and future generations}

The relationship between future generations and discounting is shortly addressed here since it is a persistent issue in discussions of intergenerational equity and environmental conservation. Ethical objections against high or even small positive discount rates have referred to shifting costs to later generations, and fewer incentives for long-term environmentally favourable projects. However, another consequence of high discount rates is discouragement of any investment in developments or projects which directly or indirectly transform or negatively affect natural environments. It is not possible to say in general what the net outcome of these two opposite effects will be (see Markandya and Pearce, 1988; and Norgaard and Howarth, 1991).

The basis for choosing a social discount rate has three dimensions: time preference, investment opportunities and uncertainty considerations. If a social rate of time preference (consumption rate of interest) and a social opportunity cost rate can be determined, the social rate of discount can be derived as a weighted average of them, adjusted for risk by adding a 'social risk premium^. Two problems then arise. First, it is not evident how a specific choice of weights should be justified. Second, the estimation of the social rate of time preference, the social opportunity cost rate, and the social risk premium poses some conceptual and practical difficulties (for a broad theoretical overview, see Lind, 1982).

The social rate of time preference can be assumed irrelevant, when a community is not seen as showing impatience, in which case individual pure time preferences are not transferable to communities. Furthermore, conceptually there is a difference between discounting over relatively short periods (smaller than the average life-time) and over multigenerational time periods. ${ }^{9}$ However, one may argue that a positive social rate of time preference is justified by expected growth rates in consumption and a positive elasticity of the marginal utility of consumption.

The opportunity cost rate will tend to be equal to the rate of time preference in a perfect market, i.e. the market interest rate. This is one reason for concentrating on opportunity costs. The opportunity cost rate may be based on the type of financing of a specific project. The discount rate may then be set equal to: (1) The social opportunity cost rate, corrected for market imperfections and externalities, if the funds for a project are obtained from the capital market; or (2) the social time preference rate (consumption rate of interest) when

\footnotetext{
${ }^{9}$ A positive discount rate implies a finite horizon. This is usually too large to be of any importance for short period considerations. However, over multigenerational problems it might have much more relevance.
} 
consumption is sacrificed (via taxation). ${ }^{10}$

Including "pure" risk in the discount rate is very restrictive, as it offers only one way of handling risk, namely as a negative exponential course (see Markandya and Pearce, 1988). Even if risk "increases monotonically", it is very unlikely to be compatible with a negative exponential pattern. Therefore, more flexible frameworks are necessary. Risk can be dealt with more appropriately in other ways than by adjustment of discount rates. The major advantage of a multi-purpose discount factor is that it simplifies the model structure.

Howarth en Norgaard (1995), in an overlapping generations context, argue that the discussion about which discount rate is best for sustainability and intergenerational equity is confusing. They regard the discount rate as an outcome of the economic processes (market price). In addition, they consider intergenerational transfers of assets or income as a more important factor in realizing sustainability. Their point is that the government may in this way adapt the intergenerational distribution of capital i.e. the market outcome. In other words, the discount rate allows for an optimal allocation, while transfers between generations allow for equity. When individuals are not purely self-interested but also show some degree of altruism towards their offspring, one may tend to think that intergenerational equity will be automatically arranged. In this case, however, there is still a need for public intervention, as one parent pair causes positive externalities on the parents of the spouse of their offspring. The main conclusion is thus that discounting is appropriate with respect to intergenerational efficiency, but not with respect to intergenerational equity. Assignment of resource rights to future generations can deal with the latter, and will affect interest rates via the market (see also Norgaard and Howarth, 1991).

\section{Sectorally disaggregated models}

Whereas growth models are generally highly aggregated, it seems useful to use disaggregated models to deal with other questions in the context of sustainable development. One of the most relevant questions is what a sustainable structure of the economy would look like in terms of sectoral distribution of output, commonly measured in monetary terms, although employment may be a relevant indicator as well. Rather than regarding such an approach as "blueprinting" one may use the outcome in a qualitative sense, namely to judge in which

\footnotetext{
10 A Iternatively, costs and benefits with possibly varying social rates of time preference may be used. However, varying rates over different investment projects may cause the problem of financial crowding out. Finally, the opportunity cost principle may apply only to small-scale, short-term projects, while if extended to big-scale, government or long-term projects it should only be compared with other long-term projects, so that lower values of opportunity cost rates result. For, both types of projects have to be carried out and should not compete too much with each other, which may imply a minor role for the discount rate.
} 
direction desirable changes would go.

A first approach is the input-output (IO) model, where sectoral interactions can be included, so that all indirect economic effects, as well as all indirect resource use and emission effects of different economic structures, in terms of final demand composition, can be calculated. Sustainable development may be included as a condition in calculating a sustainable economic structure. An important study is by Duchin and Lange (1994), where the well-known Leontief world model is extended and adapted to test the Brundtland Commission statement that growth and sustainability can go together. Their conclusion is negative, and they argue that we should rethink how to integrate development of rich and poor countries with environmental sustainability. The model is used to describe the period 1980 to 2020, and covers 16 regions, 50 sectors and dynamics in the trade of commodities, flows of capital and economic aid. Use of energy and materials (including metals, cement, pulp, paper, chemicals) are calculated as well emissions of $\mathrm{CO}_{2}$ (more than doubled worldwide over the studied period), SO (almost constant) and $\mathrm{NO}_{\mathrm{x}}$ (almost doubled).

Some Dutch examples of I-O based analysis are WRR (1987), CPB/RIVM (den Hartog and Maas, 1990) and DEOS (Dellink et al., 1996). The latter study considers alternative supplyside scenarios for 2010 reflecting different views on sustainability:

- "Strong together": focusing on sensitive ecosystems, non-material wealth, international cooperation.

- "Strong alone": strict policies for "pure domestic environmental problems"; adaptation to international standards for global and transboundary problems.

- "Negotiated sustainability": stable ecosystems and much substitution of environmental by man-made capital assumed.

- "Weak sustainability": environmental optimism, extreme substitution options assumed.

The model is based on the National Accounting Matrix including Environmental Accounts (NAMEA), developed by the Dutch Bureau for Statistics (Keuning, 1993). The I-O matrix is aggregated for the model resulting in 19 sectors. The model allows to trace impacts in terms of several important environmental (policy) themes. These include: climate change, acidification, eutrophication, ozone depletion, waste generation, wood use, water use and fishery, and land use. The model optimizes total value added (GNP) by varying the demand for the products of each sector, subject to environmental, economic and other restrictions. Each scenario generates a particular set of environmental constraints. The other restrictions 
include minimum consumption requirements, maximum productive capacity per sector, limits to trade imbalances, labour market conditions, etc. Some important results of the scenario optimizations for the period of 1991-2030 are as follows. In all scenarios economic growth is compatible with a reduction of the environmental pressure, but requires accelerated technological progress and economic restructuring. Sustainable restructuring is not necessarily conflicting with employment objectives. Environmental constraints are most influental on the outcomes in all cases, while the greenhouse problem turns out to be the most restrictive constraint. Furthermore, space may become a critical factor for future economic development in the Netherlands. The choice between the scenarios is a political one. It can certainly not proceed via a simple welfare optimization approach, but instead would require a multiobjective decision framework.

Related to the IO approach are multisectoral computable general equilibrium (CGE) models, in which interactions between sectors can be linear (input-output structure) or nonlinear (generalized production functions, such as the common nested CES). The advantage of CGE models is that they take account of all interactions, both direct and indirect, in a consistent framework. Furthermore, they particularly allow for analysis of the effects of the implementation of (regulatory) instruments for the economic structure. If the assumptions are considered to be relevant for long-run analysis (which is rather doubtful, as most of the structural characteristics are fixed), then a dynamic formulation of CGE models would perhaps be the best available standard economic tool for treating some pressing questions regarding sustainable development. However, dynamic models are complex, very datademanding and difficult to handle. Finally, it should be noted that the general equilibrium approach is the best method to address the standard environmental economics' issue of finding the optimal level of externalities. So many studies have now been performed with this method that we abstain from trying to give a survey here. Another reason for this is that optimality of externalities is not identical to sustainable development, unless preference structures and production functions incorporated in the models reflect a complete understanding of the full spectrum of environmental processes and two-way environmental-economic interactions into the future. A more explicit approach may be appropriate for this perhaps, as indicated in Crocker and Tschirhart (1992). While remaining in the CGE setting, it can formally describe the chain of economic impacts on ecosystems, ecosystem changes, and resulting effects on utilization and non-use values related to the ecosystem, thus making explicit the chain of effects commonly referred to as "environmental externalities". However, an operational 
implementation of such a plan, at an ecosystem or regional scale, would involve other disciplines than economics, and lead to integrated models. These can also be approached from an entirely different direction, as is clarified in the next section.

\section{Models of (Co-)evolution}

An alternative approach to study sustainable development comes from evolutionary economics (see Hodgson, 1993; Gowdy, 1994). The basic idea is that changes in economic reality arise so quickly, especially at a micro level, that it is impossible to have some stable, stationary or equilibrium state of the economic system. In this view also disequilibrium economics, still based on the notion of an equilibrium, is inadequate to deal with dynamicevolutionary issues. Instead, evolutionary economics views economic processes as inherently accidental, cumulative and irreversible. The method is based on Darwinian and Lamarckian evolutionary theories in biology, as well as on recent developments in evolutionary biology and Neoschumpeterian theories of technological change (Dosi et al., 1988). One important direction is that linked to behaviour and game theory in economics (Maynard Smith, 1982), while another addresses non-gradual changes leading to "punctuated equilibria" (see Gowdy, 1994).

Recently sustainable development has also studied from the perspective of evolutionary economics (Clark et al., 1995; England, 1994). The concept and model of evolution may be especially important in environmental and ecological economics with their focus on sustainable development and long-run interactions between evolving economic and ecological systems. All in all, it seems that the Darwinian, gradual and adaptive, approach dominates in evolutionary economics. It should be noted that in biology this approach has already a long time ago been replaced by a broader perspective on evolution and adaptation (see Gould and Lewontin, 1979).

Ayres (1994) and Ruth (1996) argue for an evolutionary approach that is based on physics, in particular thermodynamics, and information theory. Ayres shows a masterly combination and integration of insights from physics, geology, chemistry, biology and economics, and pays detailed attention to the evolution of capital, labour and materials in the production process. Ruth (1996) states that drawing analogies from either biology or physics has hampered progress and a scientific approach in evolutionary economics. He argues that we should focus on "non-analogy-based applications of concepts from physics", focusing on non-linear systems models and information theory indicators. He notices that some anthropocentric 
valuation issues can thus not be addressed, but that many self-organization processes in economics, characterized by chaotic dynamics and discontinuous change, can in this way be studied. However, whether it is possible to work entirely without analogies is not made clear. This seems to beg for an impossible answer to the famous philosophical questions: what is reality; and, what is a realistic approach.

Reading into evolutionary models in economics and environmental economics gives one the impression of a large variety of approaches and focal points. The key words qualitative change, structural change, uncertainty (noise, luck), diversity, mutations, selection and adaptation are essential in the argument of many contributions (although approaches are quite subjective; see Boulding, 1978; Faber and Proops, 1990; Erdman, 1993; Gowdy, 1994; Norgaard, 1994; Clayton and Radcliffe, 1996). The following summary is derived from Hodgson (1995). He regards evolution as a process consisting of three component principles, namely variation, heredity and selection. Variety and diversity, whether fully random or not, are essential, i.e. without them there can be no evolution whatsoever. Important information for discovering or speculating on evolution in actual cases will be the distribution of variations in a given population. Variation comes forth via mutations and sexual recombination. Heredity means that selected units have some degree of durability and resilience, via a mechanism that passes on characteristics to other units. If mutations or heredity can be steered (by the unit or some external actor) then we have Lamarckian (goal-oriented) evolution, which may be more appropriate as a model for economic evolution than for biological evolution, because economic actors' actions and beliefs are generally purposive. Selection and struggle for existence provide a mechanism by which relatively well adapted units can increase their numbers, either absolutely or relatively. On a population or systems level this may be regarded as selective adaptation. Selection may work on multiple levels, including individual actors, groups, routines and even institutions and policies. In this sense one can also define co-evolution of individuals and systems, such as species and ecosystems, and analogously economic activities and their natural environments. ${ }^{11}$

The evolutionary approach represents a critique on conventional economic approaches, replacing the physical-mechanistic-atomistic neoclassical approach, as in the economic growth models discussed before, by a biological-evolutionary metaphor. In evolutionary dynamics non-mechanistic, non-average and non-deterministic characteristics prevail.

\footnotetext{
${ }^{11}$ See N orgaard (1994) for a clear example of coevolution of pests, pesticide use and policies.
} 
Economic systems on all levels, notably specific sectors like computer, communication and bio-technology, show the most rapid evolution of all systems we know (physical, biological, social). This supports the belief that evolutionary modelling can help us to gain more understanding of changes in economic systems. The two most important differential characteristics of evolutionary models relative to neoclassical models are non-determinism and micro-diversity or non-average behaviour. These two characteristics can explain pathdependent or historical developments which are irreversible, i.e. where each state occurs only once. Based on these assumptions, Allen (1996; and this book) makes a distinction between three types of models, namely "deterministic" (determinism and average behaviour), "selforganizing" (non-deterministic and average behaviour), and "evolutionary" (non-deterministic and micro-diversity). Self-organizing systems can show qualitative change only on the level of collective structure (spatio-temporal organization of molecules), whereas the evolutionary type can also qualitatively change on the lowest micro-level. The latter takes place via new genotypes (genetic information or structure) reflected in new phenotypes (realized outer appearance). ${ }^{12}$

A main characteristic of evolutionary models is a vague distinction between parameters and variables (see Clark et al., 1995). This view raises some problems, however, as the respective distinction in a concrete model is always perfectly clear. This may perhaps be one reason why there is some separation between formalized and informal (historical-descriptive) approaches in the area of evolutionary economics. In modelling, reflection of evolutionary processes would essentially mean more complexity, in terms of multi-layered systems as well as number of variables and relationships between these.

When dealing with evolutionary process modelling various options are open:

(i) Integrated models with a focus on long-run interactions between economic and environmental systems, rather than on evolution of one subsystem independent of the other. Economic development is in this case made dependent upon both economic and environmental factors, which change through time and interact (van den Bergh, 1993 and 1994b). The economy is regarded as an open system with respect to physical and biological processes in all senses. Integrated models have been applied at a global scale (Meadows et al., 1972, 1982 and 1992; Barney, 1980), and at regional scales (Zuchetto

\footnotetext{
12 Path-dependence is also explained by small accidents having large consequences via positive feedback mechanisms, which in economics may relate to technological change patterns. It may be noted that path dependency can be represented by deterministic dynamic models that generate chaotic patterns.
} 
and Jansson, 1985; Braat and van Lierop, 1987; Giaoutzi and Nijkamp, 1993; Van den Bergh and Nijkamp, 1994a; Van den Bergh, 1996) and at ecosystem scales (Holling, 1978; Bockstael et al., 1995; Higgins et al., 1997a,b). Models based on materials flows are also relevant here (van den Bergh and Nijkamp, 1994b).

(ii) In much of the evolutionary economics literature, and also in the modern growth theory literature, technological progress is considered as crucial in the dynamics of both modern and developing economies. Evolutionary approaches regard technological change as an evolutionary process (Nelson and Winter, 1982; Dosi et al., 1988), dating back to ideas of Schumpeter. Such approaches aim at breaking open the black box of technology invention and temporal and spatial diffusion of innovations, using crucial information about patents for inventions and detailed statistics on changes in technologies used in specific sectors. In the context of environmental economics Faber and Proops (1990) have related long-run interactions between invention, innovation and technical progress to pollution and resource use, using a Neo-Austrian approach (see also Faber et al., 1987). This approach is similar to neoclassical economics in its assumption of rational behaviour, but it differs from it in devoting more attention to irreversibility and uncertainty. These models devote more attention to substantial and detailed issues of technological invention, innovation and diffusion than modern growth theory does.

(iii) Evolution of environmental systems (ecosystems); the main question is about the optimal management when both mechanistic and evolutionary processes occur. For instance, in agriculture the use of pesticides has a short run mechanistic effect via killing pests, and a long-run effect via changing the genotypic structure of the pest population, possibly resulting in a reduced genotypic diversity, namely domination by pest-resistant genes. This is studied by Munro (1997), adopting a deterministic modelling approach (optimal control with two state variables).

(iv) Co-evolution of environmental and economic systems based on the hierarchical and spatial structure of economy-environment systems with multiple feedback mechanisms can lead to a complex descriptive model that can be used to trace time paths that may be similar to potential or historical developments. Clark et al. (1995) illustrate the 
evolutionary dynamics in such a context for two case studies of Senegal and Crete (Greece). The main lesson from the perspective of co-evolution (Norgaard, 1994; Gowdy, 1994) seems to be that environmental policy and management should aim for preservation of biological diversity, as it leaves open more alternative evolutionary paths and reactions to future unexpected environmental problems. It is easy to extend this to cover also diversity in economic and cultural systems.

Although evolutionary models can explain qualitative, structural change, they have more trouble with resolving questions of discrete jumps on a large scale, i.e. non gradual changes (revolutions) or in the terminology of unorthodox evolutionary theory "punctuated equilibria" (see also Gowdy, 1994). The latter may be relevant in the context of sustainable development as it can be related to environmental stress and prolonged environmental change. In this sense it one could think of climate change.

Finally, evolutionary models are not supposed to be predictive, which is often regarded as a main weakness. But if evolution is the reality, no model will have much predictive power over the long run, irrespective of whether it is based on evolutionary assumptions or not. Modelling can, however, help to examine stability of systems, convergent trends, and perhaps probabilistic behaviour, using analytical models, dynamic simulation, scenario analysis and Monte-Carlo techniques. The main problem is perhaps that much of the descriptive detail of evolutionary theories cannot be formalized in models, at least not without increasing model complexity significantly. One of the main difficulties arises in dealing with complete or radical uncertainty. Such problems can partly explain why the acceptance of evolutionary modelling by economists as a useful alternative approach to studying economic phenomena has been so low. At best, evolutionary approaches offer a critique on neoclassical analysis, notably on the averaging out of variety, and on the conception of technological progress as codifyable and cumulative process, as in standard growth theory (Nelson and Winter, 1982). In a way, growth theory deals with a stable economic regime and improvements of existing technology (increasing efficiency) whereas evolutionary theory, disposing of such assumptions, essentially deals with a longer time frame. In this respect the methods are not competitive but merely complementary.

\section{Empirical issues}

For each of the above discussed approaches it is possible to either test assumptions and 
implied hypotheses or operationalize the models on basis of empirical data. Neoclassical growth models have, in spite of the enormous amount of theoretical interest shown in them, seen very few real applications. The work by Nordhaus in the context of optimal scenarios regarding climate change impacts on future economic welfare is a rare example (Nordhaus, 1994). The integrated and evolutionary models referred to in the previous section are also relevant here, as are models developed by (research) institutes for examining interactions between global environment, land use, energy use and national economies (e.g., IMAGE by Alcamo, 1994). For an overview of integrated models in the area of climate change economics see Chapter 10 in Bruce et al. (1995).

Another important line of empirical research is the investigation of specific partial or reduced-form empirical relationships between growth, economic structure and environmental stress or quality/degradation. This has taken the form of testing hypotheses, such as generated in the theoretical literature on growth (Section 3), using empirical data based on temporal or cross-section samples. The main question addressed here is whether the relationship between environmental pressure and income per capita is consistent with an inverted U-curve (or environmental Kuznets curve (EKC), referring to a similar relationship between income distribution and average income). The basic idea behind this is that higher incomes imply higher proportions being (privately or publicly) spent to environmental quality. ${ }^{13}$ Several empirical studies have been performed in this respect, mainly focusing on pollution issues rather than resource issues (for recent overviews see Stern et al., 1996; and McConnell, 1996). The results are mixed and a main conclusion is that growth does certainly not automatically lead to less pollution and that it is therefore not a panacea for environmental quality.

Where an EKC relation was assessed, the turning point in per capita income levels has been of much interest and was found to range between 1220 and 21.7001985 US dollars (McConnell, ibid.). The results can be summarized qualitatively as follows: for environmental pressure indicators related environmental problems distant in space or time (or both) there is no EKC, and pressure is commonly increasing with income (e.g., solid household waste). Pressure indicators related to nearby problems, however, like urban pollution or soil erosion, where feedback effects are usually strong, often follow a decreasing pattern against per capita income. Some main qualifications are important when trying to interpret results like these.

\footnotetext{
${ }^{13}$ For this reason M CConnell (1996) argues that the literature on nonmarket valuation may provide empirical support for the EKC mechanism as well.
} 
First, the relationships are often based on a reduced form equation, where all effects (scale, composition, technological efficiency) are aggregated, so that it is difficult to say anything about mechanisms (this requires more rigid theory testing, and possibly other techniques like decomposition analysis), and certainly about future developments for specific countries or alternative environmental issues. In addition, national level studies, either using cross-section or time-series samples, do not take into account that boundaries are open, and that trade and relocation effects may confuse the picture. Furthermore, the indicators for which inverted Ucurves are found are not necessarily related to real long-term sustainability issues characterized by resource extraction, accumulation of pollutants, dispersion of substances, and long-term impacts. A broad range of perspectives on this discussion was offered in special forums of the journals Ecological Economics (1995, vol. 15(2)), Environment and Development Economics (1996, vol. 1(1)) and Ecological Applications (1996, vol. 6(1)). These issues have invited reactions by economists and ecologists to an article in Science by a group of distinguished ecologists and economists (Arrow et al., 1995). The following statements summarize the most important positions: no environmental policy is an automatic consequence of economic growth (Clark, 1996); economic growth may be a major cause of environmental degradation, along with population growth (Daly, 1996); economic liberalization and growth policy are not substitutes for environmental policy (Arrow et al., 1995); and, the suppression of economic growth is not a suitable substitute for environmental pressure (Grossman and Krueger, 1996). For more discussion of econometric and economictheoretic aspects of the EKC studies the reader should consult McConnell (ibid.).

Another stream of literature deals with related issues, but focuses more on a disaggregate analysis of the economic structure and the material and energetic content of economic production and consumption. Terms used in this context are "dematerialization" (using less materials to create the same products and services) or "industrial metabolism" (the materials and energy flows structure of the economy; see Ayres, 1989; Herman et al., 1989; and Ayres and Simonis, 1994), and "structural change" or de-linking of growth and environmental pressure (Jänicke, 1993; De Bruyn et al., 1996).

Another line of research is the empirical work based on (static) indicators for sustainability. Pearce et al. (1996) argue that sustainability can be measured and that the search for such indicators should be guided by a theory of sustainability, notably focusing on the difference between weak and strong sustainability. The first of these is examined by green accounting exercises and calculation of green national income and saving rules (in the flavour of the 
Hartwick rule). The World Bank has genuine savings indicators for over 100 countries available now. Strong sustainability may be measured by considering carrying capacity, output variability (in agriculture) and (genetic) biodiversity in a wider sense. A valuation of man-made and natural capital can also be pursued (see Pearce and Atkinson, 1995). Various such indicators have now been calculated for both developed and developing countries (see Pearce and Atkinson, this book).

Finally, empirical research may focus on very long-run issues associated with sustainable development by performing historical analysis of various types. This may vary between rigorous statistical and purely descriptive approaches (e.g., Wilkinson, 1973; Taylor, 1977; Simmons, 1989; Ponting, 1991).

\section{Conclusions and further research}

It is not necessary to be in favour of a single type of model for investigation of sustainable development. Various types of models can deal with a range of questions and issues related to it. Optimization models with a sectoral disaggregation may help to acquire insight in the direction of structural shifts in the economy, and the effects on the level of production and consumption. Such models may even be based on simple input-output frameworks. Given certain environmental sustainability constraints, a feasible or optimal economic structure can be derived. Other, dynamic, models may be more useful when one is interested to know the adjustment over time, and stability or convergence of specific development patterns. Equilibrium growth models may say something about the consistency of dynamic paths, and allow for a calculation tool given that significant structural or qualitative change in the economy does not occur. Overlapping generations models may allow for studying policies to realize intergenerational equity. One should not search for a general type of model, with some consistent micro-basis, since reductionism is bound to fail in dealing with complex matters like sustainable development. Anyway, evolutionary approaches seem to claim reductionism to micro levels may sometimes be useful, but that macro-approaches not founded on microprocesses can be useful for specific purposes. Extreme reductionism is rejected as it is always arbitrary in its basic units, i.e. there is always a lower level of description possible. Different aggregation (or better: reductionism) levels may then be complementary.

Policy-relevant modelling for sustainable development remains a difficult issue. The gap between the economic growth models and advice needed may perhaps seem extremely large, although some people would argue that not so much specific information based on detailed 
disaggregation is needed, but merely rather general insights about, among other things, technology, investment and monetary policy. Empirical integrated or evolutionary models can hardly be developed for entire countries, and should better be restricted to well-bounded regions. On a macro-economic level multi-sector models can perhaps best follow a general equilibrium structure to arrive at qualitatively acceptable results, whereas it is probably best to keep dynamic models rather simple by focusing on particular issues (materials flows, economic productivity) or problems (global warming, resource scarcity).

Several issues deserve (more) attention in future research. First, the sustainable development of open systems has hardly been considered, which requires an interaction between interpretations of global, closed-system sustainability and regional/national sustainability. Second, in both theoretical and empirical economic research the functional specification of two types of processes should be carefully considered, and perhaps be standardized: (i) environmental processes, generally headed under the categories assimilation and regeneration; (ii) production processes which, in addition to usual inputs, include land use, materials use, energy use, biotic factors like biomass and harvested populations, and environmental factors like soil or water quality; and, (iii) mass balance conditions to take account of significant or toxic materials flows.

Historical modelling of the relationship between changes in environment and the economy may also be taken more seriously. This means examination of qualitative and possibly quantitative patterns of interaction between economy and environment over very long periods in history, rather than over only a few decades. This may generate meaningful information to make "long-run predictions" about (un)sustainable development. Also the role of long waves, raw materials supply and Schumpeterian processes of inventions and innovation in the context of long run sustainable development could be considered with such historical models in mind.

As a final suggestion, the linking of instruments to long term goals could be mentioned. Although sustainable development and environmental policy have become standard topics in textbooks now, their connection certainly deserves more research. This can focus, for example, on the role of environmental bonds, tradeable permits, intergenerational transfers, long-run public projects such as on infrastructure investments, nature policy, international agreements and policy coordination, demographic policies, and materials policy aimed at recycling and dematerialization. It is certainly easy to extend this list. 


\section{Appendix 1. A general neoclassical growth model with resources and pollution}

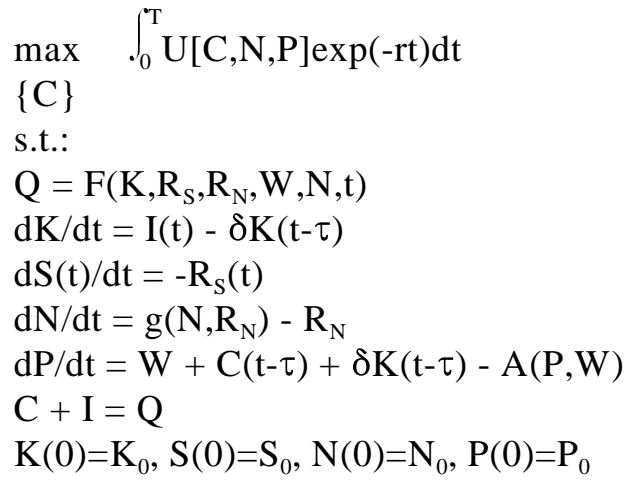

where notation has the following interpretation:

Functions:

A : rate of natural assimilation of pollution

F : instantaneous production

$\mathrm{g}$ : rate of natural regeneration

$\mathrm{U}$ : instantaneous utility

Stocks:

$\mathrm{K}$ : man-made productive capital (machines)

$\mathrm{N}$ : renewable resource stock

$\mathrm{S}$ : non-renewable resource stock

$\mathrm{P}$ : pollution stock

Flows:

$\mathrm{C}$ : value of consumption

I : value of investment

$\mathrm{Q}$ : value of production output

$\mathrm{R}_{\mathrm{S}}$ : physical non-renewables resource extraction, serving as input in production

$\mathrm{R}_{\mathrm{N}}$ : physical renewable resource extraction, serving as input in production

$\mathrm{W}$ : physical waste

$\mathrm{t}$ : time

Parameters:

$\mathrm{K}_{0}, \mathrm{~S}_{0}, \mathrm{~N}_{0}, \mathrm{P}_{0}$ are initial stock levels

$\mathrm{r}$ : time discount rate

$\delta:$ depreciation rate of productive capital

$\tau$ : time delay

Note that all variables have a time index and are non-negative. 


\section{References}

Alcamo, J. (ed.), 1994. Image 2.0: Integrated Modelling of Global Climate Change. Kluwer Academic Publishers, Dordrecht.

Allen, P., 1996. Man and the environment: The complex systems approach. Paper presented at the conference of European Environmetrics, April 11-12, 1996, Lisbon.

Arrow, K.J., 1973. Rawls' principle of just saving. Swedish Journal of Economics, vol. 75: $323-335$.

Arrow, K.J., et al., 1995. Economic growth, carrying capacity, and the environment. Science, vol. 268: 520-521.

Asako, K., 1980. Economic growth and environmental pollution under the max-min principle. Journal of Environmental Economics and Management, vol. 7: 157-183.

Ayres, R.U., 1989. Industrial metabolism, in Ausubel, J.H. and H.E. Sladovich (eds). Technology and environment, National Academic Press, Washington D.C..

Ayres, R.U. 1994. Information, Entropy and Progress: A New Evolutionary Paradigm. American Institute of Physics, AIP Press, New York.

Ayres, R.U. and U.E. Simonis (eds), 1994. Industrial metabolism, restructuring for sustainable development, United Nations University Press, Tokyo, Japan.

Baranzini, A., and F. Bourguignon, 1995. Is sustainable growth optimal? International Tax and Public Finance, vol. 2: 341-356.

Barney, G.O. (ed.), 1980. The Global 2000 Report to the President of the U.S., Entering the Twenty-first Century. 2 volumes, Penguin books, Harmondsworth.

Beltratti, A., Models of Economic Growth with Environmental Assets. Kluwer Academic Publishers, Dordrecht.

Bergh, J.C.J.M. van den, 1993. A framework for modelling economy-environmentdevelopment relationships based on dynamic carrying capacity and sustainable development feedback. Environmental and Resource Economics, vol. 3: 395-412.

Bergh, J.C.J.M. van den, 1996. Ecological Economics and Sustainable Development: Theory, Methods and Applications. Edward Elgar, Aldershot and Vermont.

Bergh, J.C.J.M. van den and P. Nijkamp, 1994a. An Integrated Model for Economic Development and Natural Environment: An Application to the Greek Sporades Islands. The Annals of Operations Research, vol. 54: 143-174. 
Bergh, J.C.J.M. van den and P. Nijkamp, 1994b. Dynamic macro modelling and materials balance: Economic-environmental integration for sustainable development. Economic Modelling, vol. 11: 283-307.

Bockstael, N., R. Costanza, I. Strand, W. Boynton, K. Bell, and L. Waigner, 1995. Ecological Economic modeling and valuation of ecosystems, Ecological Economics, vol. 14: 143-159.

Boulding, K.E., 1978. Ecodynamics: A New Theory of Societal Evolution. Sage Publications, Beverly Hills.

Bovenberg and Smulders, 1995. Environmental Quality and Pollution Saving Technological Change in a Two-sector Endogenous Growth Model, Journal of Public Economics, 57: 369391.

Braat, L.C. and W.F.J. van Lierop (eds.), 1987. Economic-Ecological Modelling. NorthHolland.

Bruce, J., et al., 1995. Climate Change 1995: Economic and Social Dimensions of Climate Change, Contribution of Working Group III, Cambridge University Press.

Bruyn, S.M. de, J.C.J.M. van den Bergh and J.B. Opschoor, 1996. Structural Change, Growth and Dematerialisation: An empirical analysis. In: J.C.J.M. van den Bergh and J. van der Straaten (eds.). Economy and Ecosystems in Change: Analytical and Historical Approaches. Edward Elgar, Aldershot and Vermont

Chichilnisky, G., 1993. What is Sustainable Development. Paper presented at the 1993 workshop of the Stanford Institute for Theoretical Economics.

Clayton, A.M.H. and N.J. Radcliffe, 1996. Sustainability: A Systems Approach. Earthscan, London.

Clark, C.W., 1996. Operational environmental policies. Environment and Development Economics, vol. 1: 110-113.

Clark, N., F. Perez-Trejo and P. Allen, 1995. Evolutionary Dynamics and Sustainable Development: A Systems Approach, Edward Elgar, Aldershot and Vermont.

Common, M. and C. Perrings, 1992. Towards an ecological economics of sustainability. Ecological Economics, vol. 6: 7-34.

Crocker, T.D. and J. Tschirhart, 1992. Ecosystems, externalities and economics. Environmental and Resource Economics, vol. 2: 551-567.

Daly, H.E., 1987. The economic growth debate: what some have learned, but many have not. Journal of Environmental Economics and Management, vol. 14: 323-336.

Daly, H.E., 1991. Steady State Economics, 2nd edition. Island Press, Washington D.C. (1st edition 1977). 
Daly, H.E., 1992. Allocation, distribution, and scale: towards an economics that is efficient, just and sustainable. Ecological Economics, vol. 6: 185-193.

Daly, H.E., 1996. Expanding an important consensus. Environment and Development Economics, vol. 1: 113-115.

Dellink, R., M. Bennis, and H. Verbruggen, 1996. Sustainable economic structures: Scenarios for sustainability in the Netherlands, W96/27, Institute for Environmental Studies, Vrije Universiteit, Amsterdam.

Devall, B. and G. Sessions, 1984. Deep Ecology. Peregrine Smith, Layton, Utah.

Dosi, G., C. Freeman, R. Nelson, G. Silverberg and L. Soete, 1988 (eds.), Technical Change and Economic Theory. Pinter Publishers, London.

Duchin, F. and G.M. Lange, in association with K. Thonstad and A. Idenburg, 1994. The Future of the Environment: Ecological Economics and Technical Change. Oxford University Press, Oxford.

England, R.W., 1994. On economic growth and resource scarcity: Lessons from nonequilibrium thermodynamics. In: R.W. England (ed.), Evolutionary Concepts in Contemporary Economics, The University of Michigan Press, Ann Arbor.

Erdman, G., 1993. Evolutionary economics as an approach to environmental problems. In: H. Giersch, (ed.), Economic Progress and Environmental Concerns. Springer-Verlag, Berlin.

Faber, M., H. Niemes and G. Stephan, 1987. Entropy, Environment and Resources: An Essay in Physico-Economics. Springer-Verlag, Heidelberg.

Faber, M. and J.L.R. Proops, 1990. Evolution, Time, Production and the Environment. Springer-Verlag, Heidelberg.

Faucheux, S., D.W. Pearce and J.L.R. Proops, 1996. Models of Sustainable Development. Edward Elgar Publishers, Aldershot and Vermont.

Georgescu-Roegen, N., 1971. Process analysis and the neoclassical theory of production. In: N. Georgescu-Roegen, Energy and Economic Myths. Pergamon, New York.: 37-52.

Giaoutzi, M. and P. Nijkamp, 1993. Decisions Support Models for Regional Sustainable Development. Avebury, Aldershot.

Goodland, R., 1995. The Concept of Environmental Sustainability, Annual Review of Ecological Systems, 26, pp. 1-24.

Gould, S.J. and R.C. Lewontin, 1979. The spandrels of San Marco and the Panglossian paradigm: A critique of the adaptationist programme. Proceedings of the Royal Society of London B, Vol. 205: 581-98. 
Gowdy, J., 1994. Coevolutionary Economics: The Economy, Society and the Environment. Kluwer Academic Publishers, Dordrecht.

Gradus, R. and S. Smulders, 1993. The trade-off between environmental care and long-term growth: Pollution in three proto-type growth models. Journal of Economics, vol. 58: 25-52.

Gross, L.S. and E.C.H. Veendorp, 1990. Growth with exhaustible resources and a materialsbalance production function. Natural Resource Modelling, vol. 4: 77-94.

Grossman, G.M., and A.B. Krueger, 1996. The inverted-U: what does it mean? Environment and Development Economics, vol. 1: 119-122.

Gutés, M.C., 1996. The concept of weak sustainability. Ecological Economics, vol. 17: 147156.

Hamilton, K., 1995. Sustainable development, the Hartwick rule and optimal growth. Environmental and Resource Economics, vol. 5: 393-411.

Harsanyi, J.C., 1955. Cardinal welfare, individualistic ethics, and interpersonal comparisons of utility. Journal of Political Economy, vol. 63: 309-321.

Hartog, H. den and R.J.M. Maas, 1990. 'A sustainable economic development: Macroeconomic aspects of a priority for the environment ${ }^{2}$. In: P. Nijkamp and H. Verbruggen (eds.), The Dutch Environment in the European Space. Stenfert Kroese, Leiden.

Hartwick, J.M., 1977. Intergenerational equity and the investing of rents from exhaustible resources. American Economic Review, vol. 67: 972-974.

Hartwick, J.M., 1978a. Investing returns from depleting renewable resource stocks and intergenerational equity. Economic Letters, vol. 1: 85-88.

Hartwick, J.M., 1978b. Substitution among exhaustible resources and intergenerational equity. Review of Economic Studies, vol. 45: 347-354.

Heal, G.M., 1996. Interpreting sustainability. Plenary presentation, 7th annual conference of the European Association of Environmental Economists (EAERE), June 27-29, 1996, Lisboa, Portugal.

Herman, R., S.A. Ardekani and J.H. Ausubel (1989). Dematerialization, in: Ausubel J.H. and H.E. Sladovich (eds). Technology and environment, National Academic Press, Washington D.C..

Hicks, J.R, 1939. Value and Capital. Oxford University Press.

Higgins, S., E. Azorin, R. Cowling, and M. Morris, 1997a. A dynamic ecological-economic model as a tool for conflict resolution in an invasive-alien-plant, biological control and native-plant scenario, Ecological Economics, vol. 22: 141-154. 
Higgins, S., J. Turpie, R. Costanza, R. Cowling, D. Le Maitre, C. Marais, and G. Midgley, 1997b. An Ecological Economic Simulation Model of Mountain Fynbos Ecosystems Dynamics, Valuation and Management. Ecological Economics, vol. 22: 155-169.

Hodgson, G.M., 1993. Economics and Evolution: Bringing back Life into Economics. Polity Press and University of Michigan Press, Cambridge and Ann Arbor.

Hodgson, G.M., 1995. Introduction. In: G.M. Hodgson, Economics and Biology. The International Library of Critical Writings in Economics Series. Edward Elgar Publishers, Aldershot and Vermont.

Hofkes, M.W., 1996. Modelling Sustainable Development: an economy-ecology integrated model, Economic Modelling, 13: 333-353.

Holling, C.S., 1973. Resilience and stability of ecological systems. Annual Review of Ecological Systems, vol. 4: 1-24.

Holling, C.S., 1978. Adaptive Environmental Assessment and Management. Wiley, New York.

Holling, C.S., 1986. The resilience of terrestrial ecosystems: Local surprise and global change. In: W.C. Clark and R.E. Munn (eds.). Sustainable development of the biosphere. Cambridge University Press, Cambridge.

Howarth, R.B., and R.B. Norgaard, 1995. Intergenerational choices under global environmental change. In: D.W. Bromley (ed.). The Handbook of Environmental Economics. Blackwell, Oxford.

Jänicke M., H. Monch, M. Binder, 1993. Ecological Aspects of Structural Change. Intereconomics Review of International Trade and Development, vol 28: 159-169.

John, A., R. Pecchenino, D. Schimmelpfennig and S. Schreft, 1995. Short-lived agents and the long-lived environment. Journal of Public Economics, vol. 58: 127-141.

Kamien, M.I. and N.L. Schwarz, 1982. 'The role of common property resources in optimal planning models with exhaustible resources`. In: V.K. Smith and J.V. Krutilla (eds.), Explorations in Natural Resource Economics. Johns Hopkins University Press, Baltimore.

Keuning, S.J., 1993. An information system for environmental indicators in relation to the national accounts. In: W.F.M. de Vries et al. (eds.). The Value Added of National Accounting. Netherlands Central Bureau of Statistics, Voorburg.

Kneese, A.V. and W.D. Schulze, 1985. Ethics and environmental economics. In: A.V. Kneese and J.L. Sweeney (eds.). Handbook of Natural Resource and Energy Economics, vol. 1, North-Holland, Amsterdam.

Lind, R. (ed.), 1982. Discounting for Time and Risk in Energy Policy. Johns Hopkins University Press, Baltimore. 
Markandya, A. and D.W. Pearce, 1988. Natural environments and the social rate of discount, Project Appraisal vol. 3: 2-12.

Maynard Smith, J., 1982. Evolution and the Theory of Games. Cambridge University Press, New York.

McConnell, K.E., 1996. Income and the demand for environmental quality. Plenary presentation, 7th annual conference of the European Association of Environmental Economists (EAERE), June 27-29, 1996, Lisboa, Portugal.

Meadows, D.H., D.L. Meadows, J. Randers and W.W. Behrens III, 1972. The Limits to Growth. Universe Books, New York.

Meadows, D.H., D.L. Meadows and J. Randers, 1992. Beyond the Limits: Confronting Global Collapse; Envisioning a Sustainable Future. Chelsea Green Publishing Co., Post Mills.

Meadows, D.H., J. Richardson and G. Bruckmann, 1982. Groping in the Dark: The First Decade of Global Modelling. Wiley, New York.

Munro, A., 1997. Economics and evolution: An introduction. Environmental and Resource Economics, vol. 10 (1).

Nelson, R. and S. Winter (1982). An Evolutionary Theory of Economic Change. The Belknap Press of Harvard University Press, Cambridge, MA.

Nordhaus, W.D., 1994. Managing the Global Commons: The Economics of Climate Change. MIT Press, Cambridge, MA.

Norgaard, R.B., 1994. Development Betrayed: The End of Progress and a Coevolutionary Revisioning of the Future. Routledge, London and New York.

Norgaard, R.B., and R.B. Howarth, 1991. Sustainability and discounting the future. In: R. Costanza (ed.). Ecological Economics: The Science and Management of Sustainability. Columbia University Press, New York.

Pearce, D.W. and G. Atkinson, 1995. Measuring sustainable development. In: D.W. Bromley (ed.). The Handbook of Environmental Economics. Blackwell, Oxford.

Pearce, D.W., E.B. Barbier and A. Markandya, 1990. Sustainable Development: Economics and Environment in the Third World. Edward Elgar Publishers, Aldershot and Vermont.

Pearce, D.W., K. Hamilton and G. Atkinson, 1996. Measuring Sustainable Development: progress on indicators, Environment and Development Economics, vol. 1: 85-101.

Perrings, C., 1991. Ecological sustainability and environmental control. Structural Change and Economic Dynamics, vol. 2: 275-295. 
Pezzey, J., 1989. Economic Analysis of Sustainable Growth and Sustainable Development. Environmental Department Working paper no. 15, Environmental Department, The World Bank. Reprinted as J. Pezzey, 1992. Sustainable Development Concepts: An Economic Analysis. World Bank Environment Paper 2.

Pezzey, 1995. The optimal sustainable depletion of non-renewable resources. Working paper, University of York, York, UK.

Ponting, C., 1991. A Green History of the World. Sinclair-Stevenson, London.

Rawls, J., 1972. A Theory of Justice. Harvard University Press, Cambridge, Mass.

Ruth, M., 1996. Evolutionary economics at the crossroads of biology and physics. Journal of Social and Evolutionary Systems, Vol. 19: 125-144.

Simmons, I.G., 1989. Changing the Face of the Earth: Culture, Environment, History. Basil Blackwell, Oxford.

Solow, R.M., 1974. Intergenerational equity and exhaustible resources. Review of Economic Studies, vol. 41: 29-45.

Solow, R.M., 1986. On the intergenerational allocation of natural resources. Scandinavian Journal of Economics, vol. 88: 141-149.

Stern, D.I., M.S. Common and E.B. Barbier, 1996. Economic growth and environmental degradation: The Environmental Kuznets Curve and sustainable development. World Development, Vol. 24: 1151-60.

Tahvonen, O. and J. Kuuluvainen, 1991. Optimal growth with renewable resources and pollution. European Economic Review, vol. 35: 650-661.

Tahvonen, O. and J. Kuuluvainen, 1993. Economic growth, pollution and renewable resources. Journal of Environmental Economics and Management, vol. 24: 101-118.

Taylor, A.M., 1977. The historical evolution of mankind's inner and outer dimensions. In: E. Laszlo and J. Bierman (eds.). Goals in a Global Community, Vol. I. Pergamon Press, New York, pp. 65-116a.

Toman, M.A., J. Pezzey and J. Krautkraemer, 1995. Neoclassical economic growth theory and "sustainability". In: D. Bromley (ed.), Handbook of Environmental Economics. Blackwell, Oxford, 1994.

Turner, R.K., C. Perrings and C. Folke, 1996. Ecological economics: paradigm or perspective. In: J.C.J.M van den Bergh and J. van der Straaten, 1996. Economy and Ecosystems in Change: Analytical and Historical Approaches, Edward Elgar, Aldershot and Vermont.

WCED, 1987. Our Common Future. World Commission on Environment and Development, Oxford University Press, Oxford/New York. 
WRR, 1987. Capacity for Growth: Opportunities and Threats for the Dutch Economy in the Next Ten Years. Wetenschappelijke Raad voor het Regeringsbeleid, rapporten aan de regering 1987/29, Staatsuitgeverij, The Hague (in Dutch).

Wilkinson, R., 1973. Poverty and Progress: An Ecological Model of Economic Development, Methuen \& Co., London.

Young, C.E.F., 1996. Effective Demand and "Weak" Sustainability: A Macroeconomic Model. In: J.C.J.M van den Bergh and J. van der Straaten, 1996. Economy and Ecosystems in Change: Analytical and Historical Approaches, Edward Elgar, Aldershot and Vermont.

Zuchetto, J. and A.M. Jansson, 1985. Resources and Society: A Systems Ecology Study of the Island of Gotland, Sweden. Springer-Verlag, New York. 